\title{
Two stents for simultaneous esophageal and gastric cancer
}

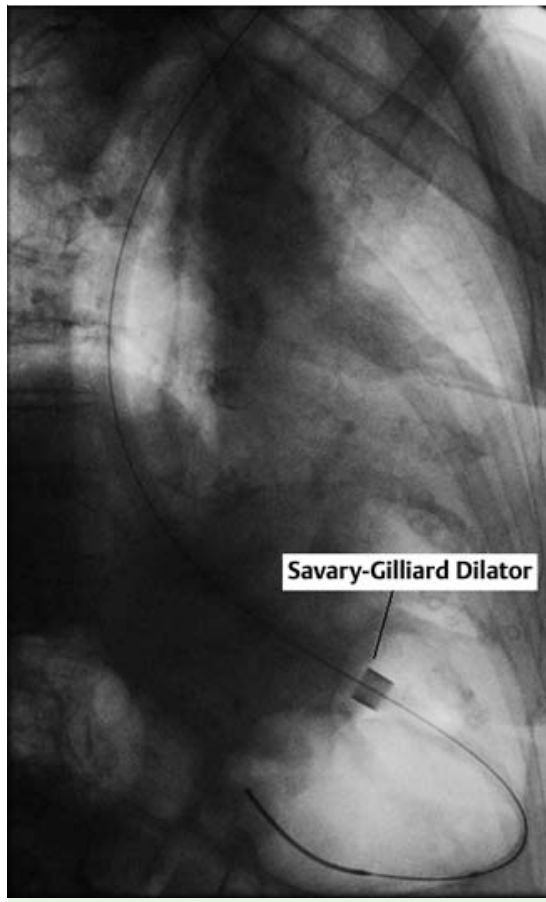

Fig. 1 Savary-Gilliard dilation of the gastrointestinal junction obstructed by tumor in a 91-year-old woman.

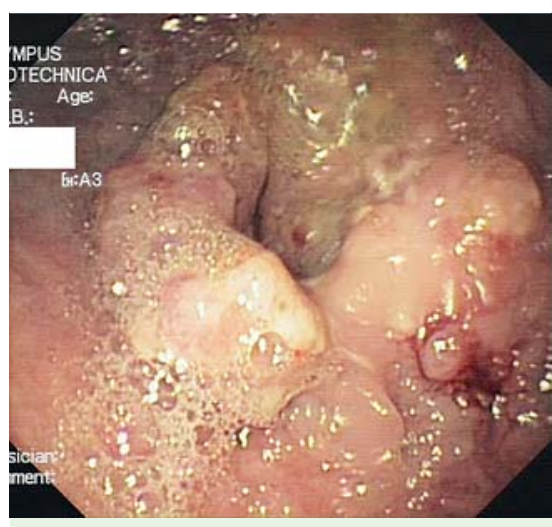

Fig. 2 Synchronous tumor in the gastric antrum: prepyloric and also nearly obstructing.

Simultaneous isolated tumors of the esophagus and stomach can occur as synchronous tumors or as intramural metastases of one of the tumors. Although most esophageal and gastric cancers share some risk factors, and although they are the most frequently associated cancers, actual synchronicity is very rare $[1,2]$. We describe the first case of synchronous

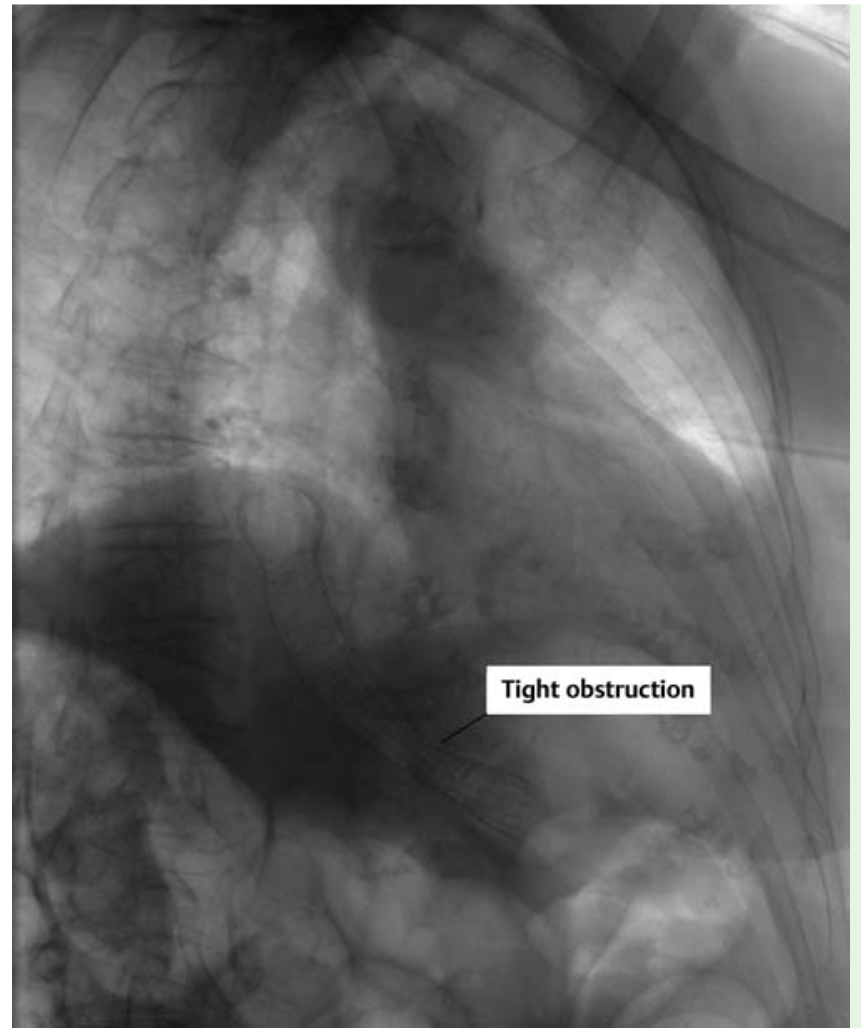

Fig. 3 Tight obstruction at the gastrointestinal junction. The stent did not open fully at first.

endoscopic insertion of stents for synchronous obstructing tumors.

A 91-year-old woman was admitted to an outside hospital with progressive solidfood dysphagia, vomiting, and weight loss. Upper endoscopy showed an obstructing tumor at the gastrointestinal junction. Due to her advanced age and high surgical risk, the patient was transferred to our institution for palliative stent placement.

On repeat endoscopy, the tumor at the gastrointestinal junction (squamous cell carcinoma) nearly obstructed passage of the gastroscope. A Savary-Gilliard dilation up to $11 \mathrm{~mm}$ was performed ( $\bullet$ Fig. 1 ), allowing the gastroscope to pass. However, in the gastric antrum, a second, prepyloric and also nearly obstructing synchronous tumor was discovered ( $\bullet$ Fig. 2). Although with difficulty, the gastroscope was passed into the duodenum.

After discussion, we decided to insert two separate stents. A therapeutic gastroscope could not be passed through the obstruction at the gastrointestinal junction, so a first stent (Ultraflex, partially covered, 100/18 mm; Boston Scientific, Natick, Massachusetts, USA) was inserted across the junction. The obstruction was so tight that the stent would not open fully and a therapeutic scope could not pass ( $\bullet$ Fig.3). The procedure was stopped and a new examination was scheduled for the following week in order to allow the nitinol stent to open fully with time.

On the third endoscopy, the therapeutic scope now easily passed through the gastrointestinal junction stent, and a second stent (pyloroduodenal Wallstent, 90/ $22 \mathrm{~mm}$; Boston Scientific) was inserted across the second, prepyloric tumor (an adenocarcinoma) ( $\bullet$ Fig.4).

Two months later, the patient was alive and eating solid food without dysphagia or vomiting.

Endoscopy_UCTN_Code_TTT_1AO_2AZ

\section{Competing interests: None}




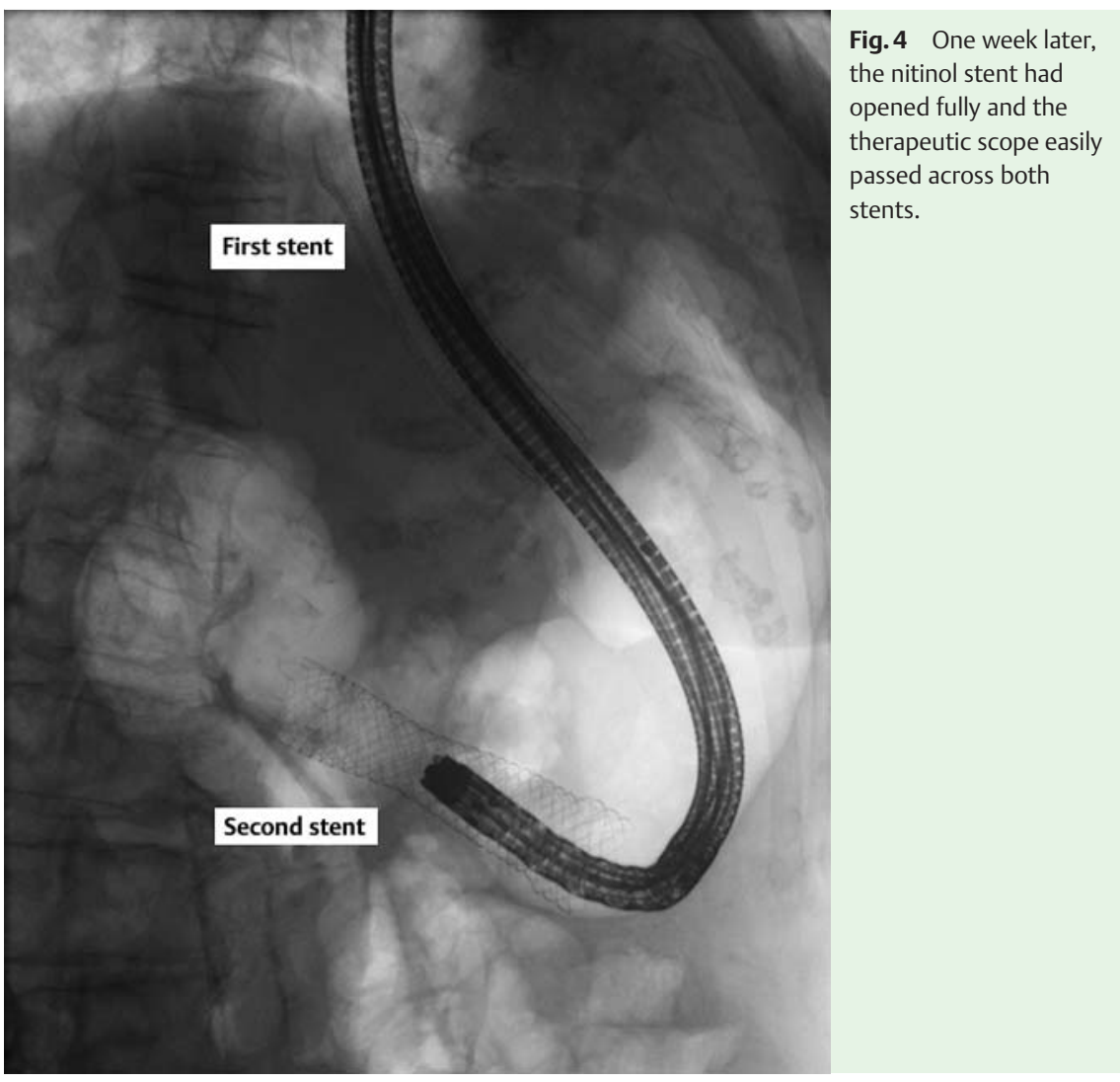

\section{lyad Khamaysi, Ian M. Gralnek}

Department of Gastroenterology, Rambam Health Care Campus and Rappaport Faculty of Medicine, TechnionIsrael Institute of Technology, Haifa, Israel

\section{References}

1 Pasławski M, Złomaniec J, Rucińska E et al. Synchronous primary esophageal and gastric cancers. Ann Univ Mariae Curie Sklodowska Med 2004; 59: 406-410

2 Koide N, Adachi W, Koike S et al. Synchronous gastric tumors associated with esophageal cancer: a retrospective study of twentyfour patients. Am J Gastroenterol 1998; 93: $758-762$

\section{Bibliography}

Dol http://dx.doi.org/

10.1055/s-0033-1359124

Endoscopy 2014; 46: E101-E102

(c) Georg Thieme Verlag KG

Stuttgart · New York

ISSN 0013-726X

\section{Corresponding author lyad Khamaysi, MD}

Department of Gastroenterology

Rambam Medical Center

Haifa 31096

Israel

Fax: +972-4-8543058

k_iyad@rambam.health.gov.il 